\title{
Mother and fetal immunity to cytomegalovirus
} Arnaud Marchant

\author{
Address: Institute for Medical Immunology, Université Libre de Bruxelles and ImmuneHealth, Charleroi, Belgium \\ from Fifth Dominique Dormont International Conference. Mother-to-child transmitted viral diseases: from transmission to children care \\ Paris, France. 26-28 March 2009 \\ Published: 22 July 2009 \\ Retrovirology 2009, 6(Suppl I):L3 doi:10.1 186/1742-4690-6-SI-L3
}

This abstract is available from: http://www.retrovirology.com/content/6/SI/L3

(C) 2009 Marchant; licensee BioMed Central Ltd.

The pathogenesis of cytomegalovirus (CMV) transmission in utero remains poorly understood. Identification of the mechanisms involved and of biomarkers of transmission would help in the design and in the "proof of concept" evaluation of vaccine candidates. Primary CMV infection during pregnancy induces the differentiation of CD4 and CD8 $\mathrm{T}$ lymphocytes producing anti-viral cytokines. In contrast, proliferative responses of $\mathrm{CD} 4 \mathrm{~T}$ cells are acquired slowly and are associated with a reduced risk of transmission. Defective CD4 T lymphocyte responses could allow the replication of CMV in organs involved in transmission and may limit the development of neutralising antibody responses. The development of severe symptoms and the prolonged viral excretion observed following CMV infection during fetal life may be related to defective immune responses. Mature CD8 T lymphocyte responses to CMV can be detected in infected newborns. In contrast, $\mathrm{CMV}$ induces the expansion and the differentiation of fetal CD4 $\mathrm{T}$ lymphocytes that are unable to produce anti-viral cytokines or proliferate in response to viral antigens. Our current understanding of mother and fetal immunity to CMV suggests that the virus interferes with the acquisition of specific functions of CD4 $\mathrm{T}$ lymphocytes, particularly during the early phase of the infection. The different expression of this interference in mothers and fetuses may involve the immaturity of antigen-presenting cells. 